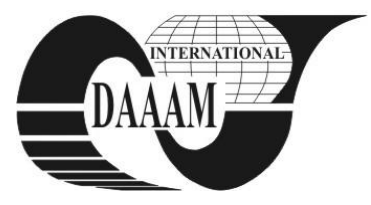

Annals of DAAAM for 2012 \& Proceedings of the 23rd International DAAAM Symposium, Volume 23, No.1, ISSN 2304-1382 ISBN 978-3-901509-91-9, CDROM version, Ed. B. Katalinic, Published by DAAAM International, Vienna, Austria, EU, 2012 Make Harmony between Technology and Nature, and Your Mind will Fly Free as a Bird

\title{
SELECTION OF CUTTING MATERIAL FOR MILLING OF FERRITIC - MARTENSITIC STAINLESS STEEL TOOL WEAR VS. ROUGHNESS OF MACHINED SURFACE
}

\author{
FULEMOVA, J[aroslava] \& JANDA, Z[denek]
}

\begin{abstract}
The article deals with influence of tool wear on roughness of machined surface during finishing machining of ferritic-martensitic stainless steel. A dividing plane of steam turbine body is machined under specific cutting conditions and with a special cutting tool. There are really strict requirements on this dividing plane, namely on the roughness of machined surface and also on the cutting tool. The aim is to find the cutting tool which is able to machine this difficult-to-machine material under the highest cutting conditions regarding to input information.
\end{abstract}

Keywords: milling, tool wear, roughness, ferritic-martensitic steel

\section{INTRODUCTION}

The trend in a power industry is increasing energy efficiency at decreasing of pollutant emission. It is possible to achieve it by increasing of working parameters of steam. Only a few construction materials can work under these conditions. Ferritic-martensitic stainless steel is ranked among them. Steel, which is marked as EN ISO X12CrMoVNbN9-1 and which is well known under trade mark P91, belongs to this group. There is little information about this steel in books and on the internet, because it is relatively a new material in comparison to other stainless steels. The material P91 was invented in the eighties however as material of pipelines (tubes, vertical bend, collars) for power and chemical industry. That is why, this material was first known under trade mark T91 (tube). Within last few years, material 91 started to use as a construction material for steam body turbines especially for highpressure parts and all of it because of its very good mechanical properties.

Meanwhile it is used only in limited supply in comparison to common structural steels. On that account no one has dealt with its machining till now. If there is a published article about this material these days (05/2012) it is about looking for other modifications $(60 \%$ of published articles) and about moulding and welding of this material ( $40 \%$ of published articles). If the producers are obliged to use the material they have to find appropriate cutting conditions and a cutting material to reach suitable roughness of machined surface and it is not easy, because to find the information needs a lot of time and money. This article describes the experimental choice of an appropriate cutting material for machining of a dividing plane of steam turbine body regarding roughness of machined surface.

\section{EXPERIMENTAL CONDITIONS}

There are shown experimental conditions in the Tab.1. The experiment was done under these conditions. The constants were these conditions: $\mathrm{fZ}=4.5 \mathrm{~mm}$ (feed per tooth); $\mathrm{aP}=0.02 \mathrm{~mm}$ (axial depth of cut). These values are used during real machining. The next point is that these values are recommended cutting conditions by the producer of inserts. For the best chip flow from the cutting area there was external cooling. There was only a one insert in the cutter head, because it was necessary to remove the influence of insert's dimensional inaccuracy or the cutter head on machined surface. The radial depth of cut during the experimental machining was ae $=50$ $\mathrm{mm}$ and it was face milling. The own experiment was divided into two parts.

The first part was to select two or three kinds of inserts from eight possibilities and then to do wide experimental tests for these two or three inserts. At first part there were determined two experimental criteria: maximal tool wear $\mathrm{VBB} / \mathrm{VBN}=0.2 \mathrm{~mm}$ and roughness of machined surface $\mathrm{Ra}<0.8 \mu \mathrm{m}$. At the beginning we co-operated with producer of cutting inserts who recommended us eight kinds of different cutting materials. Six kinds of sintered carbide (SC-A, SC-B, SC-C, SC-D, SC-E and SC-F) and two kinds of cermets (CM-A and CM-B). The inserts were with wiper geometry and they were tangential.

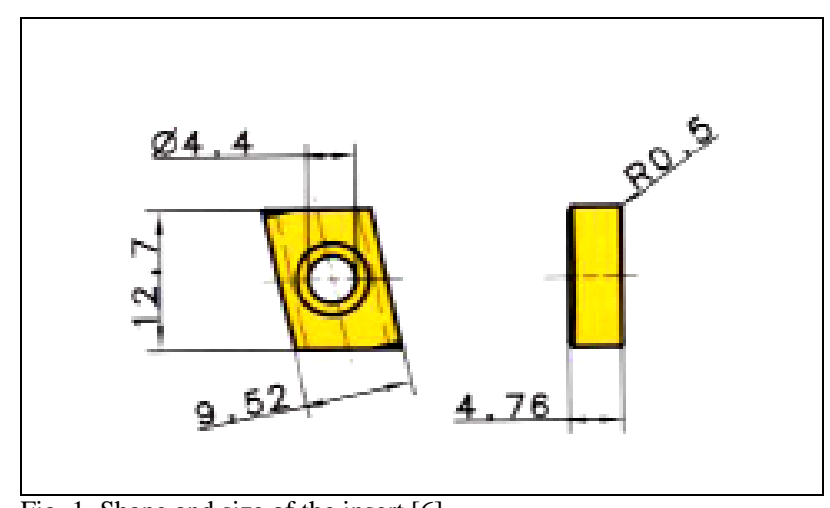

Fig. 1. Shape and size of the insert [6]

A cutting speed $\mathrm{vC}$ was chosen regarding the values which were recommended by producer of inserts. These values are border values of cutting speed $\mathrm{vC}$ from interval of recommended values. 


\begin{tabular}{|c|c|}
\hline \multicolumn{2}{|c|}{ Experimental conditions } \\
\hline \multicolumn{2}{|c|}{ PRE-EXPERIMENT } \\
\hline cutting material & sintered carbide \\
\hline $\mathrm{v}_{\mathrm{c}}\left[\mathrm{m}_{\mathrm{min}}{ }^{-1}\right]$ & $150 \mathrm{a} 226$ \\
\hline $\mathrm{n}\left[\mathrm{min}^{-1}\right]$ & $600 \mathrm{a} 900$ \\
\hline $\mathrm{f}_{\mathrm{z}}[\mathrm{mm}]$ & 4.5 \\
\hline $\mathrm{v}_{\mathrm{f}}\left[\mathrm{mm} \cdot \mathrm{min}^{-1}\right]$ & $2700 \mathrm{a} 4050$ \\
\hline $\mathrm{a}_{\mathrm{p}} / \mathrm{a}_{\mathrm{e}}[\mathrm{mm}]$ & $0.02 / 50$ \\
\hline cooling & external \\
\hline number of inserts & 1 \\
\hline \multicolumn{2}{|c|}{ climb milling } \\
\hline
\end{tabular}

\begin{tabular}{|c|c|}
\hline \multicolumn{2}{|c|}{ Experimental conditions } \\
\hline \multicolumn{2}{|c|}{ PRE-EXPERIMENT } \\
\hline cutting material & cermets \\
\hline $\mathrm{v}_{\mathrm{c}}\left[\mathrm{m}_{\mathrm{min}}{ }^{-1}\right]$ & 150,200 a 250 \\
\hline $\mathrm{n}\left[\mathrm{min}^{-1}\right]$ & 600,800 a 1000 \\
\hline $\mathrm{f}_{\mathrm{z}}[\mathrm{mm}]$ & 4.5 \\
\hline $\mathrm{v}_{\mathrm{f}}\left[\mathrm{mm} \cdot \mathrm{min}^{-1}\right]$ & $2700,3600 \mathrm{a} 4500$ \\
\hline $\mathrm{a}_{\mathrm{p}} / \mathrm{a}_{\mathrm{e}}[\mathrm{mm}]$ & $0.02 / 50$ \\
\hline cooling & external \\
\hline number of inserts & 1 \\
\hline \multicolumn{2}{|c|}{ climb milling } \\
\hline
\end{tabular}

Tab.1. Chosen cutting conditions for pre-experiment - for Sintered carbide (left) and for cermets (right)

\begin{tabular}{|l|c|l|}
\hline Type & Application field & \multicolumn{1}{|c|}{ Characterization } \\
\hline SC-A & K10 - K25 & a)WC / TiAlN \\
\hline SC-B & $\begin{array}{c}\text { M15 - M35, K20 - } \\
\text { K40 }\end{array}$ & b)WC / AlTiN \\
\hline SC-C & $\begin{array}{c}\text { P10 - P20, K10 - } \\
\text { K25 }\end{array}$ & WC / AlTiN \\
\hline SC-D & P20 - P40 & c)WC / TiN \\
\hline SC-E & P20 - P40 & d)WC / TiAlN \\
\hline SC-F & K10 - K25 & e)WC / without coating \\
\hline CM-A & $\begin{array}{c}\text { P05 - P15, M05 - } \\
\text { M15 }\end{array}$ & f)TiN \\
\hline CM-B & P10 - P30 & g)without coating \\
\hline
\end{tabular}

Tab.2. Information about cutting material

\subsection{Tool life of cutting tool}

In Fig. 2 there is done mutual comparison of a tool life for particular tested inserts. The tool life is described through the use of volume of removal material B which was removed at the time of the tool life for the one cutting edge. The test for the cutting edge was finished, when there was reached the criteria value of tool wear. The criteria value of the cutting edge was set to $\mathrm{VBB} / \mathrm{VBN}=0.2 \mathrm{~mm}(200 \mu \mathrm{m})$. The test was also finished in the case when the volume of removal material reached $\mathrm{V}=108 \mathrm{~cm} 3$. The volume of removal material is more than three times higher than the volume of removal material in the real conditions.

All types of inserts were more worn on the flank than on the tool face. The value of tool wear on the flank has significant influence on the quality of machined surface, especially on the roughness of machined surface [3].

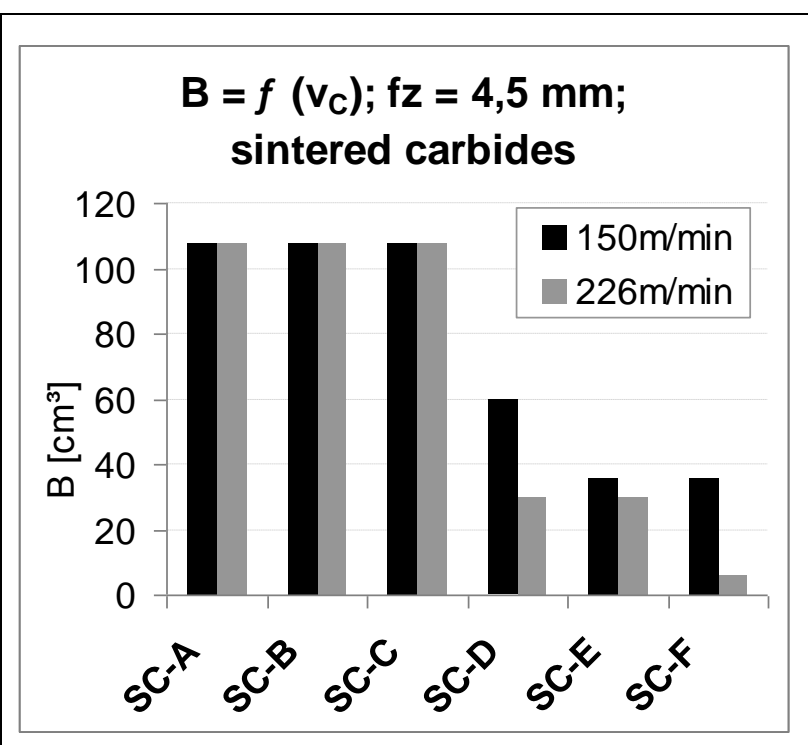

\section{$B=f\left(v_{C}\right) ; f z=4,5 \mathrm{~mm}$ CERMETs}

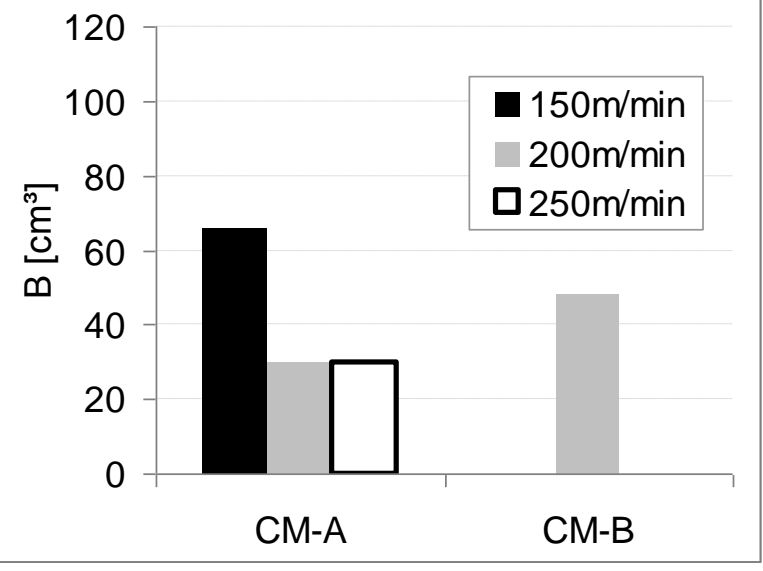

Fig.2. Comparison of tool wear for each cutting material, sintered carbides (left), cermets (right)

\subsection{Roughness of machined surface}

In the case of finishing machining the roughness of machined surface is the second most important criteria for the selection of the most suitable cutting material. The roughness of machined surface is very important for the dividing plane of steam body turbine. The criteria value of roughness of machined surface is $\mathrm{Ra}=0.8 \mu \mathrm{m}$ and in the case of finishing machining the roughness of machined surface is directly dependent on the tool wear. Strictly speaking on the flank wear VBN. Generally it is well known that roughness of machined surface is getting better with increasing cutting speed [1, 2, 3], it does not always have to be truth.

Positive influence of increasing cutting speed on the roughness of machined surface is obtained especially in cases when there are used inserts of common construction and the main influence on the resultant roughness of machined surface has cutting conditions. In our case there were used inserts with special kind of construction, so-called "inserts with wiper geometry". 


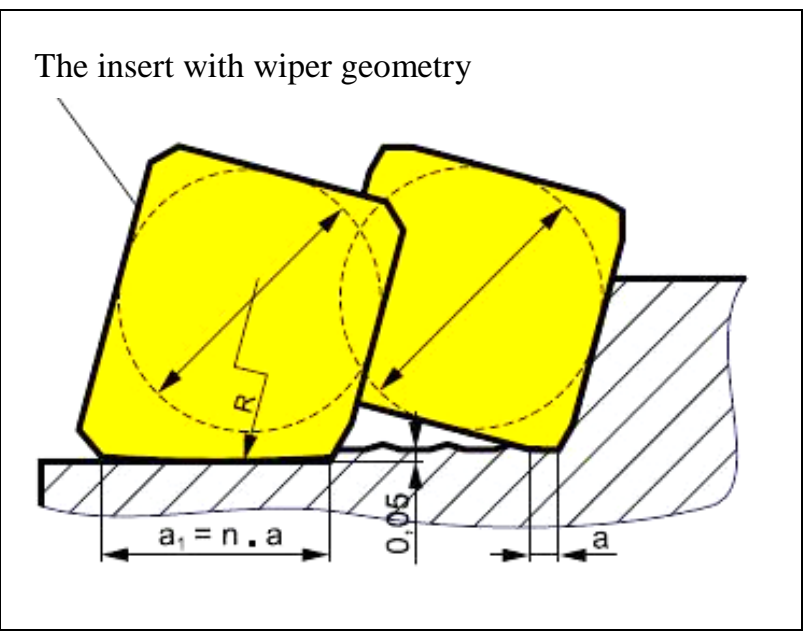

Fig.3. Comparison of the insert with wiper geometry and the insert of common construction [5]

The main task of these special inserts is to reach the best quality of machined surface under all kinds of cutting conditions $[1,4,5]$. The difference between the insert with wiper geometry and the insert of common construction can be seen in the Fig. 3 .

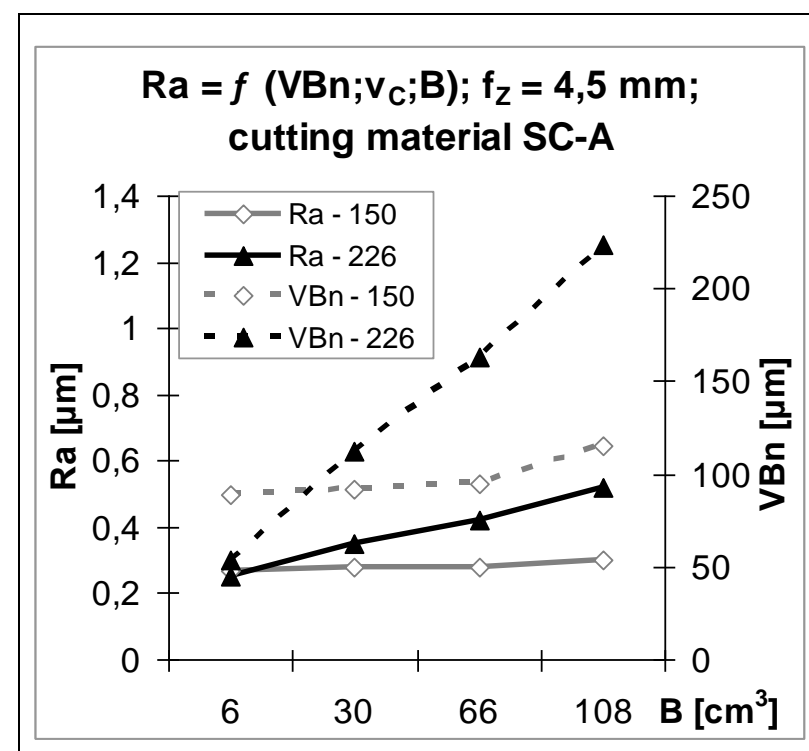

$\mathrm{Ra}=f\left(\mathrm{VBn} ; \mathrm{v}_{\mathrm{C}} ; \mathrm{B}\right) ; \mathrm{f}_{\mathrm{Z}}=4,5 \mathrm{~mm}$; cutting material SC-B

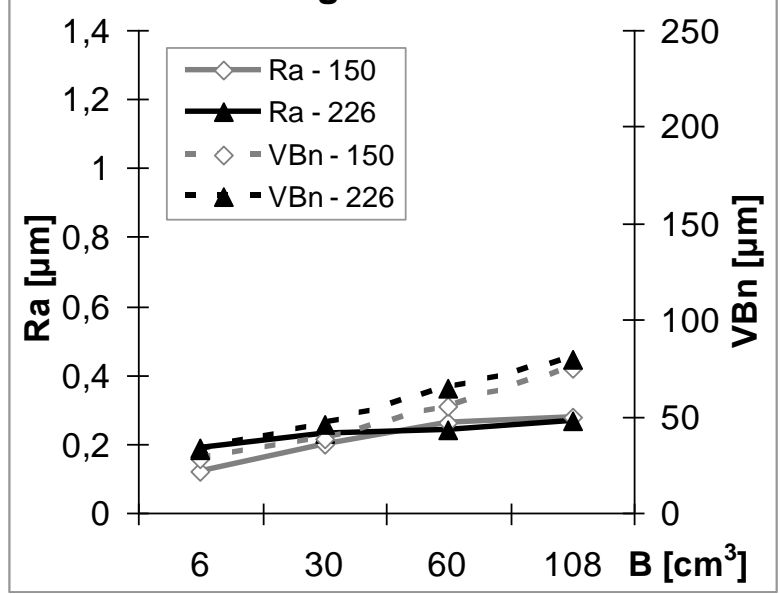

Fig. 4. Relation of the roughness of machined surface Ra and the toll wear on the flank of the tool VBN: SC-A and SC-B
Increasing of cutting speed $\mathrm{vC}$ has more likely negative influence on the roughness of machined surface in the case of using the insert with wiper geometry. The value of cutting speed $\mathrm{vC}$ has significant influence on the tool life of the cutting edge, thus on the size of tool wear. The tool wear has significant influence on the roughness of machined surface. In this case there was found significant dependence roughness of machined surface on the tool wear of the cutting edge. This dependence is shown in the Fig. 4, but it is done only for two cutting materials (SC-A and SC-B).

The continuous lines are used for behaviour of roughness $\mathrm{Ra}$ and the dashed lines are used for behaviour of tool wear VBN. As you can see in the Fig. 4 and Fig. 5 the size of tool wear on the flank of the tool VBN directly influences roughness of machined surface and holds the higher size of tool wear the worse roughness of machined surface, in this case we used parameter Ra.

Increasing of a cutting speed $\mathrm{vC}$ has negative influence on a tool life. The tool starts to wear more intensively and that is why the increasing cutting speed means the worse roughness of machined surface.

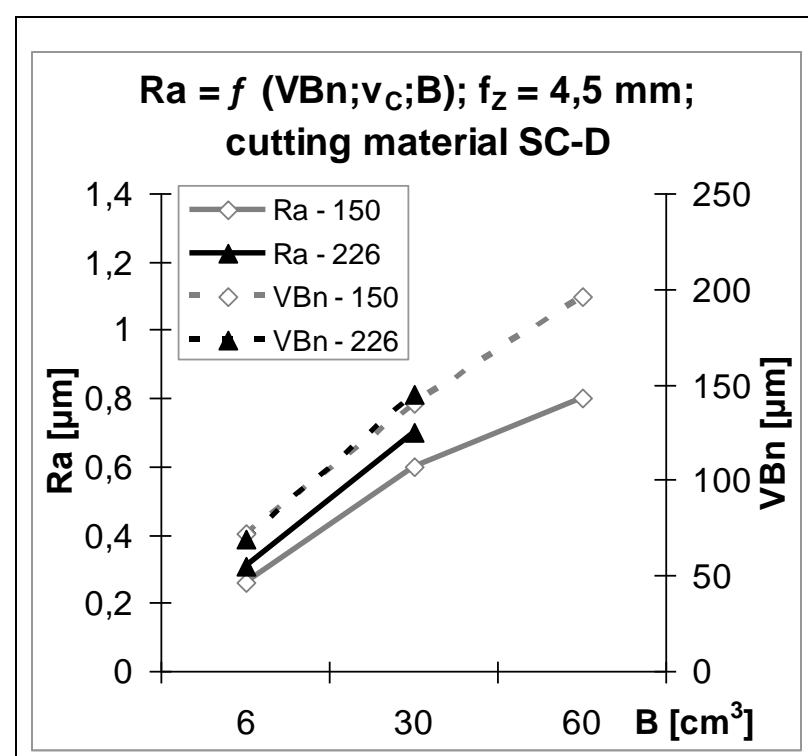

\section{$\mathrm{Ra}=f\left(\mathrm{VBn} ; \mathrm{v}_{\mathrm{C}} ; \mathrm{B}\right) ; \mathrm{f}_{\mathrm{Z}}=4,5 \mathrm{~mm}$; cutting material CM-A}

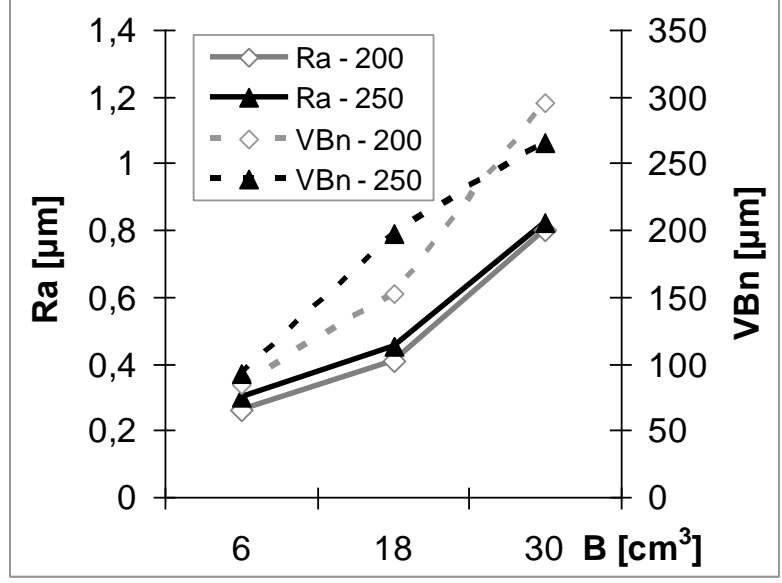

Fig. 5. Relation of the roughness of machined surface $\mathrm{Ra}$ and the toll wear on the flank of the tool VBN: SC-D and SC-A 
During machining of dividing plane of steam body turbine it is very important to keep specified parameters of machined surface. Especially roughness of machined surface which does not have to cross the value of $\mathrm{Ra}=$ $0.8 \mu \mathrm{m}$.

In term of requirement on the steam tightness it is also very important that the reached roughness of machined surface has to be the same on the whole dividing plane of the steam body turbine. The roughness of machined surface should not dramatically change depending on the volume of removal material (tool path). Therefore as the more suitable cutting materials are those, which were able to reach relatively the same roughness of machined surface depending on the volume of removal material. Those are SC-A, SC-B and SC-C.

\section{CONCLUSION}

For machining of steel P91, under the tested cutting conditions, the most suitable cutting material is coated sintered carbide. Regarding the character of machining there are allowed to use only milling heads of big size and these milling heads must be fixed by inserts. During our tests the best materials were double-barrelled substrates (WC) with lower content of Co. The cutting material reaches better results when there is suitable thin layer which is coated on the tool.

The best system of coating is PVD (Physical Vapour Deposition) with system AlTiN. Cermets are not suitable kind of cutting material for machining of this steel. During machining of stainless steels there is an area where the built-up-edge comes up. It is necessary to avoid this area. In the case of machining steel P91 the area of build-up-edge comes up at the cutting speed $226 \mathrm{~m} / \mathrm{min}$. There are two areas of suitable cutting speeds. Some cutting materials have potential to work under higher cutting speeds and some of them not. This is the aim of other tests.

Future plans for next research: This article presents just a part of our research. A lot of work was done about machining of the steel P91. The first part was about semi-finishing machining, where the main tasks were to find an appropriate cutting material, select maximal two candidates and find cutting conditions for machining of steel P91 with these cutting materials. The second part of experiments was similar. The first step was to select cutting materials (which you can find in this article) and the next part will be to find the most effective cutting conditions for these cutting materials during machining of steel P91. After that all our results will be tested in the company for which we do this research and experiments. The tests will be done on a real body steam turbine under the cutting conditions which will be recommended.

After all of the experiments the next part will start. We will focus on the cutting edge and its preparation. It is well known that cutting edge preparation can improve productivity of cutting process. At these days an overwhelming majority of tool producers are focused on cutting edge preparation, because this preparation can positively influence:

a) tool life

b) strength of cutting edge

c) minimal chipping of cutting edge

d) preparation of cutting edge to deposition

e) creating of defined shape and measurement of cutting edge

f) etc.

So the next part of experiments will be focused on the optimal cutting edge radius, the suitable technology for preparation of cutting edge and $\mathrm{K}$ factor. The input information for experiments will be the same: depth of cut $0.02 \mathrm{~mm}$ ! This number is very important.

\section{ACKNOWLEDGEMENTS}

This paper is based upon work sponsored by the student project grant competition no.SGS/2012/023.

\section{REFERENCES}

[1] Salihu, A.; Zeqiri, H.; Bunjaku, A.; Qehaja, N.; Osmani, H. \& Zeqiri, F.:Research of the height parameters of the machined surface, Annals of DAAAM for 2011 \& Proceedings of the 22nd International DAAAM Symposium, ISBN 978-3-901509-83-4, ISSN 1726-9679, pp 1055-1056, Editor B[ranko] Katalinic, Published by DAAAM International, Vienna, Austria 2011

[2] Shao, H., Liu, L., Qu, L.: Machinability study on $3 \% \mathrm{Co}-12 \% \mathrm{Cr}$ stainless steel in milling; Wear 263 (2007); Elsevier, 2007

[3] *** (2009) DAVIM, J.P.: Surface integrity in Machining; Portugal: Springer London, 2009. ISBN 978-1-84882-873-5

[4] *** (2005) SANDVIK COROMANT. Technical handbook of machining. AB Sandvik Coromant, 2005

[5] *** (2005) SANDVIK COROMANT. Technická př́ručka obrábění. AB Sandvik Coromant, 2005

[6] *** (2004) PRAMET: Handbook of machining; 2004

[7] *** (2004) PRAMET: Příručka obrábění; 2004

[8] *** (2012) Catalogue Ingersoll 